Section Editors

David C. Spencer, MD

Steven Karceski, MD

Jeffrey A. Switzer, DO

\title{
Detecting paroxysmal atrial fibrillation after stroke
}

An ischemic stroke results from blockage of an artery in the brain. There are many causes of an ischemic stroke. Determining the cause guides treatment to prevent future strokes. One common cause of stroke is an abnormal heart rhythm called atrial fibrillation (AF). AF causes as many as 1 in 5 strokes. $\mathrm{AF}$ is diagnosed by recording the heart rhythm with an EKG. To prevent stroke from AF, a medicine called warfarin is used. However, AF can come and go, and a patient may not feel anything. When this happens, $\mathrm{AF}$ is called paroxysmal $A F$ (PAF). If a stroke patient has PAF and it is not detected, the risk of a future stroke increases.

WHAT DID THE AUTHORS STUDY? Recently, doctors have used technology to monitor stroke patients outside of the hospital. In a study in this issue of Neurology ${ }^{\circledR}$, researchers looked at the frequency of PAF after stroke using a device called a transtelephonic EKG monitor (TTM). ${ }^{1}$ TTM is a pocket-sized device with dry electrodes that stick to the chest wall. When a patient presses a button, the device will record a 30-second EKG. The patient can send the EKG to a receiving center by dialing the center and holding the device up to the phone. The authors reviewed the records of patients admitted to their stroke center. All patients had been diagnosed with a stroke or TIA. A TIA is like a stroke but the symptoms go away quickly. All patients had been tested to determine the cause of their stroke or TIA. This testing included a brain MRI and a 24-hour EKG monitor. Patients with known AF or heart disease as the cause of their stroke were not included in the study. All subjects used TTM for 1 month. Patients in the study used the device at least once per day. If PAF was detected by the receiving center, patients were contacted and told to use the device every 2 hours until the heart rhythm normalized.

WHAT WERE THE RESULTS? Among the 98 patients studied, TTM detected 17 episodes of PAF in
9 patients (9\%). Episodes lasted from 4 to 72 hours. The researchers found that certain MRI and 24-hour EKG results performed earlier in the hospital increased the likelihood of detecting PAF. PAF was detected in $43 \%$ of patients with both risk factors and none of the patients with neither risk factor. All patients with PAF were treated with warfarin.

WHAT DOES THIS MEAN FOR STROKE PATIENTS? The cause of stroke in many stroke patients is still unknown. In patients with PAF, results of a 24-hour EKG and Holter monitor may be normal. Several studies have shown that the detection of PAF after stroke increases with additional heart monitoring after patients leave the hospital. For patients with stroke of unknown cause, extended heart monitoring with TTM or other devices may be useful to diagnose PAF. If you or your family member has had a stroke, ask your doctor whether further testing for $\mathrm{PAF}$ is needed. In patients with confirmed PAF, warfarin reduces the risk of future stroke.

WHAT FURTHER RESEARCH IS NEEDED? The next step is to determine the ideal type and length of heart monitoring after stroke to detect PAF. Should monitors continuously record activity for 24 hours per day, or are 30-second strips (like TTM) adequate? For how long should stroke patients be monitored? Some monitors can be implanted under the skin and collect data for more than a year. However, only a small portion of stroke patients will have PAF. Which patients are most likely to have PAF and should be tested? Also, sometimes very brief episodes of PAF ( $<30$ seconds) are found. Do these episodes have the same long-term risk of stroke as longer episodes? Do these brief episodes require treatment with warfarin?

\section{REFERENCE}

1. Gaillard N, Deltour S, Vilotijevic B, et al. Detection of paroxysmal atrial fibrillation with transtelephonic EKG in TIA or stroke patients. Neurology 2010;74:1666-1670. 
Section Editors

David C. Spencer, MD

Steven Karceski, MD

\section{About remote evaluation of stroke patients}

Ischemic stroke results from the sudden blockage of an artery within the brain. Blood flow is reduced downstream from the blockage, and brain cells starve. Strokes occur suddenly and often without warning. Therefore, stroke is an emergency. The immediate goal of treatment is to break up the stroke-causing clot and restore blood flow to the brain. Only 1 drug has been proven to work in stroke, and this clot-busting drug works only if given in the first few hours after symptom onset. Delays from stroke onset to treatment lessen the chance of a good outcome.

\section{REMOTE NEUROLOGIC EVALUATION FOR} STROKE Evaluation and treatment of stroke requires expertise from neurologists and stroke specialists. However, many rural and community hospitals lack doctors with specialty training in stroke. Because acute stroke treatment is an emergency, patients may be transferred to hospitals with stroke experts. This is not ideal. Time is lost during travel and treatment is delayed. Instead, stroke experts may be contacted by phone to make treatment recommendations. However, the inability to see the patient and view scans makes decision making difficult.

TELESTROKE To improve early stroke treatment, neurologists and other specialists use telemedicine to evaluate patients from a distance (figure 1). The use of telemedicine for stroke is referred to as telestroke. Telestroke allows experts to examine patients, talk with patients and families, and review scans, laboratory results, and vital signs. Decisions regarding early stroke management can be made and treatment can be started without delay. Patients can stay at their local hospital and close to home or be transferred to a larger center based on their condition and needs. Telestroke is an integral part of stroke systems of care. The American Stroke Association recommends telestroke for acute stroke decision making when local expertise is not available.

\section{REMOTE CARDIAC MONITORING FOR STROKE}

Strokes occur for many reasons. Arteries within the brain and arteries that supply blood to the brain can form clots that halt blood flow. Clots can also form in the heart and travel within the blood to the brain where they become lodged. The most common reason for clots to form in the heart is an irregular heart rhythm called atrial fibrillation (AF). AF can be persistent or may come and go. Some patients may have symptoms such as a feeling of irregular heartbeats or shortness of breath. Others will be unaware that they have AF. When AF comes and goes, it is referred to as paroxysmal $A F$ (PAF). To reduce the risk of stroke in
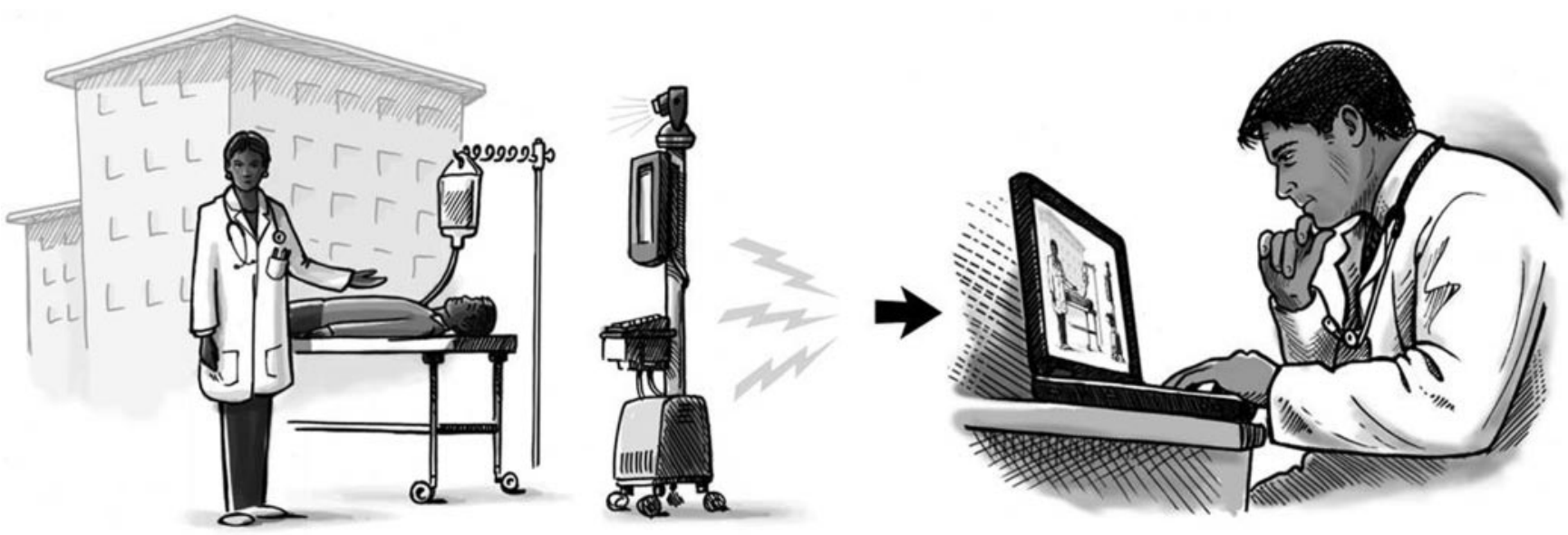


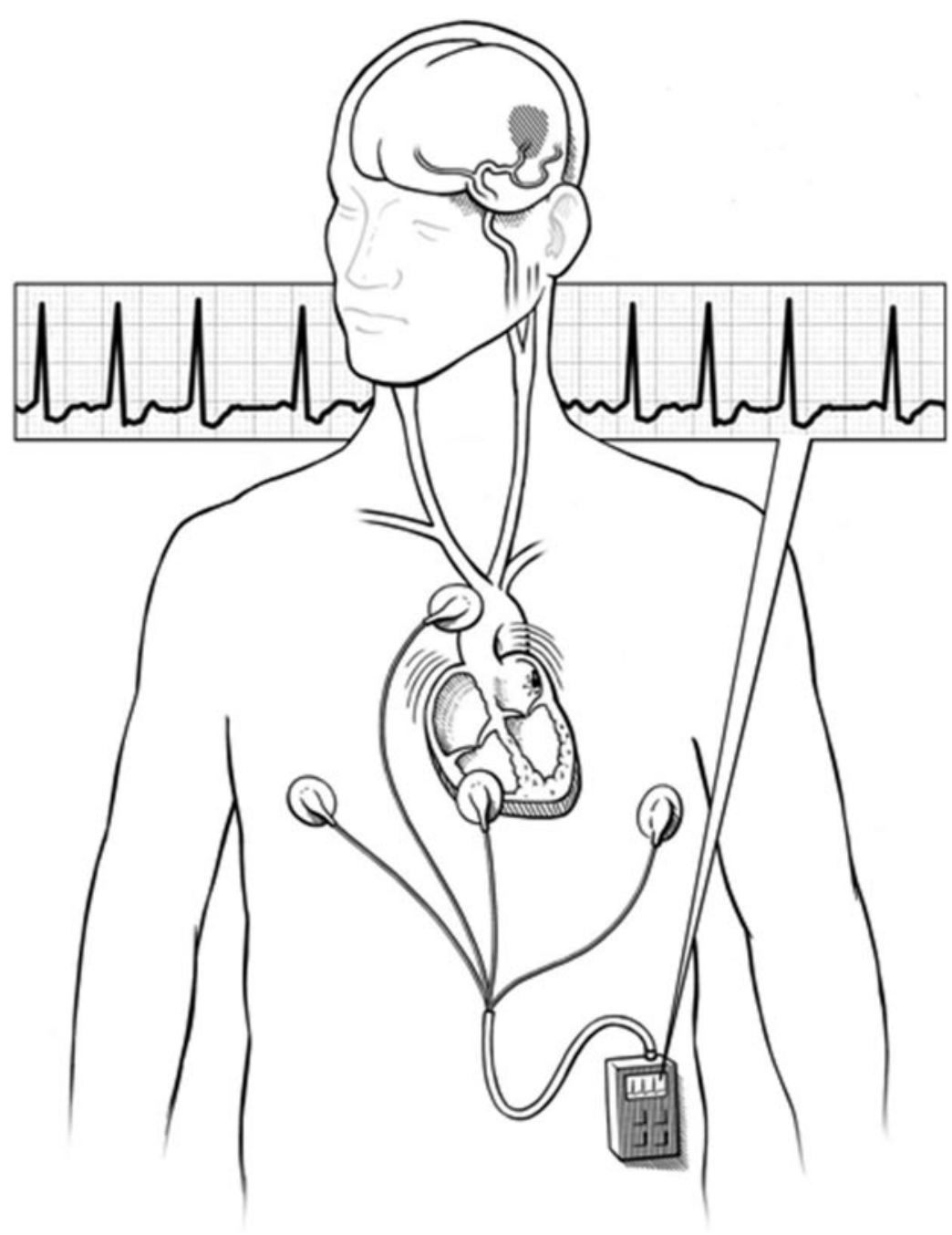

patients with PAF, a drug called warfarin is used. If PAF is not detected, warfarin is typically not prescribed, and the risk of future stroke increases.
CARDIAC RHYTHM MONITORS AF is diagnosed using an EKG. However, PAF may be missed on a standard 30-second EKG strip. To diagnose PAF, a longer recording may be needed. This can be done in the hospital or after discharge. Between 5\% and 20\% of selected stroke patients have PAF diagnosed only after extended heart monitoring.

Several different devices can be used to monitor heart rhythm after stroke (figure 2). These devices are portable, allowing patients to wear the monitor outside of the hospital. Holter monitors record continuous heart rhythm activity for 24 to 48 hours. Cardiac event monitors and mobile cardiac telemetry can be worn for up to 30 days. These devices can be triggered by the patient or may trigger automatically if an abnormal rhythm occurs. Device data can be transferred to a receiving center using standard telephone lines, cellular telephones, or the Internet. Last, implantable loop recorders may be inserted under the skin and record heart activity for up to 2 years.

Research is needed to select which stroke patients will benefit from a cardiac event monitor, what type of monitor is best, and how long to monitor.

\section{FOR MORE INFORMATION}

AAN.com for Patients \& Caregivers

http://patients.aan.com/

National Stroke Association

http://www.stroke.org/site/PageNavigator/HOME

American Stroke Association

http://www.strokeassociation.org/presenter.jhtml:identifier= 1200037

National Institutes of Neurologic Disorders and Stroke

http://stroke.nih.gov/

Heart Rhythm Society

http://www.hrsonline.org/ 


\section{Neurology}

\section{Detecting paroxysmal atrial fibrillation after stroke Jeffrey A. Switzer \\ Neurology 2010;74;e94-e96 \\ DOI 10.1212/WNL.0b013e3181e0ef2e}

\section{This information is current as of May 24, 2010}

\section{Updated Information \& Services}

References

Subspecialty Collections

Permissions \& Licensing

\section{Reprints}

including high resolution figures, can be found at: http://n.neurology.org/content/74/21/e94.full

This article cites 1 articles, 1 of which you can access for free at: http://n.neurology.org/content/74/21/e94.full\#ref-list-1

This article, along with others on similar topics, appears in the following collection(s): All Cerebrovascular disease/Stroke http://n.neurology.org/cgi/collection/all_cerebrovascular_disease_strok e Other cerebrovascular disease/ Stroke http://n.neurology.org/cgi/collection/other_cerebrovascular_disease_st roke

Information about reproducing this article in parts (figures,tables) or in its entirety can be found online at:

http://www.neurology.org/about/about_the_journal\#permissions

Information about ordering reprints can be found online: http://n.neurology.org/subscribers/advertise

Neurology ${ }^{\circledR}$ is the official journal of the American Academy of Neurology. Published continuously since 1951, it is now a weekly with 48 issues per year. Copyright . All rights reserved. Print ISSN: 0028-3878. Online ISSN: 1526-632X.

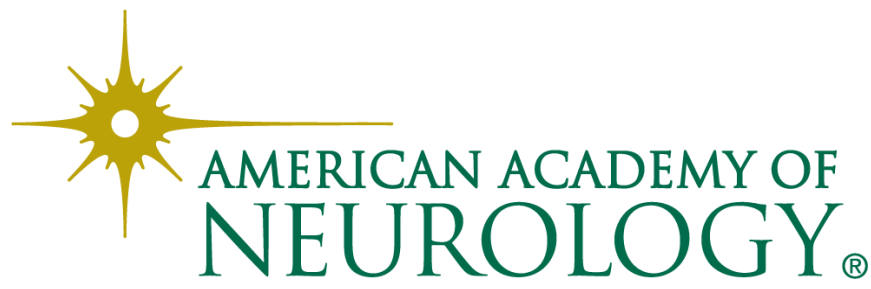

